DOI: 10.4274/jarem.galenos.2020.3453

J Acad Res Med 2020;10(3):214-9

\title{
Role of Red Cell Distribution Width in Evaluation of Inflammatory Bowel Disease Activity
}

\author{
(1) Deniz Öğütmen Koç11, (10) Murat Keğin² \\ ${ }^{1}$ University of Health Sciences Turkey, Gaziosmanpaşa Training and Research Hospital, Clinic of Gastroenterology, İstanbul, Turkey \\ 2University of Health Sciences Turkey, Gaziosmanpaşa Training and Research Hospital, Clinic of General Surgery, İstanbul, Turkey
}

Cite this article as: Öğütmen Koç D, Keğin M. Role of Red Cell Distribution Width in Evaluation of Inflammatory Bowel Disease Activity. J Acad Res Med 2020;10(3):214-9

\begin{abstract}
Objective: We aimed to determine whether red cell distribution width (RDW) is useful in evaluating the activity and remission periods of inflammatory bowel disease (IBD).

Methods: One hundred thirty-two IBD patients, consisting of 98 ulcerative colitis (UC) patients and 34 Crohn's patients, were included in this retrospective study. Serum C-reactive protein (CRP) level, erythrocyte sedimentation rate (ESR), leukocyte and platelet counts and hemoglobin (Hb) concentrations were evaluated separately during disease activity and remission periods. Disease activity for UC and Crohn's disease was determined by Mayo score and Crohn's Disease Activity Index (CDAl), respectively.

Results: The median age (interquartile range) was 37.5 (29-50) and the duration of the disease was $29.4 \pm 44.3$ months in the patients included in the study. RDW, ESR, CRP values, leukocyte and thrombocyte counts were significantly active periods compared to remission periods ( $<<0.01)$, while $\mathrm{Hb}$ concentration was significantly lower $(p<0.001)$. ESR, CRP, and platelet levels were significantly associated with Mayo score in UC patients and CDAl severity in Crohn's patients $(p<0.05)$. No association was observed between RDW and disease severity according to IBD activity scores. RDW, ESR, CRP values and platelet counts were significantly higher during the active periods of patients with UC (36.7\%) and Crohn's disease (41.2\%) with anemia than those without anemia $(p<0.01)$.

Conclusion: RDW can be used as an indicator of activity and remission in IBD patients. RDW can be a useful additional marker as an easy and inexpensive tool to monitor disease activity, predict relapse, and follow-up treatment.
\end{abstract}

Keywords: Red blood cell distribution width, inflammatory bowel disease, activity, remission

\section{INTRODUCTION}

Inflammatory bowel disease (IBD) is a chronic inflammatory disease of the gastrointestinal system that occurs with periods of activity and remission throughout its clinical course (1). It contains 2 main phenotypes: Crohn's disease and ulcerative colitis (UC). UC is characterized by inflammation limited to the colon mucosa, while in Crohn's disease, transmural inflammation is observed, which can affect any part of the gastrointestinal tract (2). In IBD patients, the value of hemoglobin $(\mathrm{Hb})$ concentration and platelet count and inflammation markers such as erythrocyte sedimentation rate $(E S R), C$-reactive protein (CRP) were reported in disease activity assessment and treatment effectiveness monitoring $(3,4)$. Recent studies have highlighted the possible role of red cell distribution width (RDW) as an additional inflammatory marker in IBD (5-7). RDW is a measure of the size variability and heterogeneity

ORCID IDs of the authors: D.Ö.K. 0000-0003-2738-625X; M.K. 0000-0002-0596-2386. 
(anisocytosis) of erythrocytes in peripheral blood. RDW, which is part of a whole blood count, is a blood parameter that is routinely measured, automatically reported. It is obtained by dividing the standard deviation of the erythrocyte volume distribution by the mean corpuscular volume (MCV) and multiplying by 100 (8). RDW is being used as an auxiliary index in the diagnosis of anemias caused by iron deficiency, B12 or folic acid deficiencies; this has led to it being considered as a potential screening marker for colon cancer and celiac disease (9-11).

Recently, RDW has been shown to have clinical significance for evaluating the clinical consequences and severity of various pathological conditions such as cardiovascular and respiratory diseases, sepsis, malignancies, renal dysfunction, autoimmune diseases, and $(11,12)$ has been found to be a strong predictor of mortality in cardiovascular diseases (13). It has also been observed to be important in assessing mortality rates and survival in hospitalized patients and to be a prognostic biomarker in adults 45 years and older $(12,14)$. Systemic factors that alter erythrocyte homeostasis, such as inflammation and oxidative stress, are thought to play a role in the mechanisms underlying RDW's association with survival (14). High oxidative stress can reduce the survival of erythrocytes, so that a higher-grade anisocytosis can be observed due to the increased proportion of immature erythrocytes in circulation (15). In addition, the relationship between the increase in systemic inflammation and anisocytosis supports the role of RDW as an important inflammatory marker (11).

In this study, we compared RDW values measured during the activity and remission periods of IBD patients. We aimed to determine whether RDW can be used as a marker in activity monitoring and recurrence prediction of IBD patients.

\section{METHODS}

A total of 132 patients IBD patients who were hospitalized or followed as outpatients were included in this study. Medical records of the patients were reviewed retrospectively. Malignancy, rheumatic diseases, acute infectious diseases, cardiovascular diseases and patients who did not continue the follow-up were excluded from the study. The study group consisted of 98 (74.2\%) patients with UC and 34 (25.8\%) patients with Crohn's disease. During periods of activity and remission, serum RDW, CRP, ESR values, leukocyte and platelet counts, $\mathrm{Hb}$ concentration, mean platelet volume (MPV), MCV, and iron ( $\mathrm{Fe}$ ) results were evaluated. Disease activity for UC and Crohn's disease was determined with Mayo score and Crohn's Disease Activity Index (CDAl), respectively. UC patients according to Mayo score: (1) remission $<3$; (2) 3 $\leq$ mild activity <6; (3) $\geq 6$, moderate-severe activity. Crohn's patients according to CDAl: (1) remission <150; (2) $150 \leq$ mild activity <220; (3) $\geq 220$, moderate-to-severe activity. The presence of normal disease activity scores, tests, and clinical findings in patients was accepted as remission. Anemia was defined as $\mathrm{Hb}$ levels below $12 \mathrm{~g} / \mathrm{dL}$ and $13 \mathrm{~g} / \mathrm{dL}$ for female and male patients, respectively.
The analysis of the data was approved by the Ethics Committee of Taksim Training and Research Hospital, which verified that the study complies with the ethical rules of the Declaration of Helsinki (approval number: 36, date: 10.04.2019).

\section{Statistical Analysis}

The compatibility of numerical variables to normal distribution was tested with the Shaphiro-Wilk test. Student's t-test was used to compare normally distributed variables in two independent groups. The paired t-test was used to test the difference between two dependent measurements in normally distributed variables. Relationships between numerical variables were tested with Pearson correlation coefficient, and relationships between categorical variables were tested with chi-square test. SPSS Windows 22.0 package program was used in the analyzes. $P<0.05$ was considered significant.

\section{RESULTS}

Median age (interquartile range) was 37.5 (29-50) and disease duration was $29.4 \pm 44.3$ months in 132 patients included in this retrospective observational study. Twenty (58.8\%) of the Crohn's patients were male and $57(58.2 \%)$ of the UC patients were male. The general characteristics of the patients are given in Table 1. Distribution according to disease location in UC patients is as follows: 23 (23.5\%) patients proctitis, 41 (41.8\%) left sided colitis and 34 (34.7\%) patients pancolitis. In Crohn's patients, 19 (55.9\%) patients had terminal ileitis and 15 (44.1\%) patients had ileocolitis. There were no significant differences in age, gender, and duration of disease between UC and Crohn's patients ( $p>0.05)$. When patients were evaluated for anemia, 14 (41.2\%) of Crohn's patients and 36 (36.7\%) of UC patients had anemia, there was no significant difference in the presence of anemia between the two groups $(p>0.05)$. In addition, there was no difference in RDW, ESR, CRP values, platelet count and $\mathrm{Hb}$ concentration during activity and remission periods between UC and Crohn's patients ( $p>0.05$ ).

RDW values were significantly higher in active periods of IBD patients compared to remission periods ( $p=0.007)$. In addition, while ESR, CRP values, leukocyte and thrombocyte counts were significantly higher in IBD patients during their active periods when compared with their remission periods $(p<0.001) ; \mathrm{Hb}$ concentrations, MPV and Fe values were significantly lower in the active period $(p<0.001)$. There was no significant difference in $M C V$ values between the activity and remission periods $(p>0.05)$. When UC and Crohn patient groups were evaluated separately; RDW, CRP, ESR values, leukocyte and platelet counts were found to be significantly higher in the activity period of both groups (Table 2).

According to the disease localization, there was no significant difference in RDW values between patients with proctitis, leftsided colitis, and pancolitis for UC diseases; and between patients with terminal ileitis and ileocolitis for Crohn's disease ( $p>0.05)$. CRP, ESR and leukocyte values were found to be higher in the 
pancolitis group compared to the left-sided colitis and proctitis groups in the active period of UC $(p=0.004, p=0.014, p=0.029$, respectively). There was no significant difference in inflammatory markers between ileitis and ileocolitis patients in the active period of Crohn's ( $p>0.05)$. In our study, in terms of $\mathrm{Hb}$ concentrations in UC patients, a significant difference was found between the groups with mild, moderate and heavy activity in the Mayo score $(p=0.003)$, but no difference was found between the mild and moderate-severe CDAl groups in Crohn's patients ( $p=0.105)$. ESR, CRP values and platelet counts increased significantly in parallel with Mayo score and CDAl severity, while no significant differences in RDW values were observed in both groups ( $p>0.05$ ) (Table 3).

\begin{tabular}{|c|c|c|c|}
\hline & Ulcerative colitis $(n=98)$ & Crohn $(n=34)$ & $p$ \\
\hline Gender (M/F) (n) & $57 / 41$ & $20 / 14$ & 0.556 \\
\hline Duration of the disease, month & $29.7 \pm 45.9$ & $28.3 \pm 39.9$ & 0.869 \\
\hline \multicolumn{4}{|l|}{ Localized disease, (n, \%) } \\
\hline - Left side colitis & $41(41.8)$ & - & - \\
\hline - Pancolitis & $34(34.7)$ & - & - \\
\hline - Terminal ileitis & - & $19(55.9)$ & - \\
\hline - Ileocolitis & - & $15(44.1)$ & - \\
\hline
\end{tabular}

Table 2. Comparative analysis of inflammatory markers in IBD patients by activity and remission

\begin{tabular}{|c|c|c|c|c|c|c|}
\hline & \multicolumn{3}{|c|}{ Ulcerative colitis $(n=98)$} & \multicolumn{3}{|l|}{ Crohn $(n=34)$} \\
\hline & Activity & Remission & $p$ & Activity & Remission & $p$ \\
\hline $\mathrm{Hb}(\mathrm{g} / \mathrm{dL})$ & $12.9 \pm 1.9$ & $13.6 \pm 1.7$ & $<0.001^{\star}$ & $12.9 \pm 2.2$ & $13.6 \pm 1.8$ & $0.009 *$ \\
\hline WBC $\left(10^{3} / \mathrm{mm}^{3}\right)$ & $8.3 \pm 2.7$ & $7.0 \pm 1.9$ & $<0.001^{*}$ & $8.4 \pm 2.1$ & $7.3 \pm 1.7$ & $0.002^{*}$ \\
\hline $\operatorname{PLT}\left(10^{3} / \mathrm{mm}^{3}\right)$ & $298.2 \pm 112.4$ & $268.2 \pm 81.1$ & $0.002^{*}$ & $336.0 \pm 115.7$ & $278.0 \pm 67.4$ & $0.002^{*}$ \\
\hline RDW (\%) & $15.3 \pm 3.0$ & $14.6 \pm 2.1$ & 0.050 & $16.0 \pm 3.5$ & $14.9 \pm 2.0$ & $0.047^{\star}$ \\
\hline
\end{tabular}

Table 3. Comparative analysis of inflammatory markers according to disease activity in IBD patients

\begin{tabular}{|c|c|c|c|c|c|c|c|}
\hline & \multicolumn{4}{|c|}{ Ulcerative colitis ( $n=98$ ) } & \multicolumn{3}{|l|}{ Crohn $(n=34)$} \\
\hline & \multicolumn{4}{|l|}{ Mayo score } & \multicolumn{3}{|l|}{ CDAl } \\
\hline & Mild $(n=12)$ & $\begin{array}{l}\text { Moderate } \\
(n=24)\end{array}$ & Severe $(n=62)$ & $p$ & Mild $(n=12)$ & $\begin{array}{l}\text { Moderate-severe } \\
(n=22)\end{array}$ & $p$ \\
\hline $\mathrm{Hb}(\mathrm{g} / \mathrm{dL})$ & $13.7 \pm 1.8$ & $13.8 \pm 1.4$ & $12.4 \pm 2.0$ & $0.003^{*}$ & $13.8 \pm 2.1$ & $12.4 \pm 2.1$ & 0.105 \\
\hline WBC $\left(10^{3} / \mathrm{mm}^{3}\right)$ & $6.9 \pm 1.3$ & $7.7 \pm 2.6$ & $8.7 \pm 2.8$ & 0.051 & $8.3 \pm 1.8$ & $8.5 \pm 2.3$ & 0.652 \\
\hline CRP (mg/dL) & $3.9 \pm 1.1$ & $4.3 \pm 1.7$ & $27.8 \pm 45.4$ & $0.010^{*}$ & $11.7 \pm 15.1$ & $51.4 \pm 56.8$ & $0.001^{*}$ \\
\hline RDW (\%) & $14.8 \pm 1.5$ & $14.5 \pm 2.7$ & $15.7 \pm 3.2$ & 0.230 & $14.8 \pm 2.5$ & $16.7 \pm 3.8$ & 0.200 \\
\hline
\end{tabular}


diagnosis of anemias caused by iron deficiency, B12 or folic acid deficiencies $(17,18)$. In addition, there is an increase in RDW in cases such as severe blood loss that causes immature cells to be released into the bloodstream, hemoglobinopathies that cause erythrocyte shape change, hemolytic anemia or hemolysis $(12,13)$.

The mechanisms mediating the relationship between high RDW values and IBD activity are not exactly known. Chronic inflammatory condition, causing immature erythrocytes to enter the circulation, can contribute to ineffective erythropoiesis and lead to increased RDW $(14,16)$.

In IBD, proinflammatory cytokines such as interleukin-1b (IL1b), IL-6, IL-10, tumor necrosis factor alpha and interferon gamma are produced by peripheral blood monocytes and mononuclear cells of the intestinal lamina propria (19-21). These cytokines may contribute to the development of anemia by inducing erythropoietin resistance (22). Also during inflammatory processes, the biological half-life of erythrocytes is reduced as a result of oxidative stress and lipid peroxidation. This promotes erythrophagocytosis and reduces iron recirculation. These facts lead to the retention of iron in phagocytes and the development of functional iron deficiency, that is, although iron is present in the body, it is not present for erythropoiesis (23). At the same time, more inflammatory activity probably leads to greater blood loss, increased hepcidin release, and decreased iron absorption from the intestine (24). These factors cause immature red blood cells to be released into the peripheral circulation, leading to an increase in RDW and anisocytosis (13).

In our study, we showed that increased RDW levels are associated with disease activity in IBD. We found that RDW increased during the activity periods of IBD patients and returned to normal in the remission period. Cakal et al. (5) showed that a $14 \%$ cut value for RDW had a sensitivity of 0.86 and a specificity of 0.75 when detecting active UC, and a 14.1\% RDW cut value for Crohn's disease had a sensitivity of 0.78 and a specificity of 0.63 .

As expected in the results of our patients, inflammatory markers such as ESR, CRP values, leukocyte and platelet numbers were significantly higher during the IBD active period. ESR, CRP values and platelet counts were higher in the group with severe Mayo score in UC patients and in the group with moderate-severe CDAl in Crohn's patients. But no significant association was found between RDW and disease activity scores.

by automated laboratory equipment used to perform complete blood counts (8). Recently, RDW value has been used in the

\section{Table 4. Comparison of inflammatory markers in active IBD patients with anemia status}

\begin{tabular}{|c|c|c|c|}
\hline & \multicolumn{3}{|l|}{ IBD $(n=132)$} \\
\hline & Anemia $(n=50)$ & No anemia $(n=82)$ & $p$ \\
\hline CRP (mg/dL) & $41.9 \pm 59.6$ & $12.8 \pm 18.9$ & $0.001 *$ \\
\hline ESR (hours) & $42.7 \pm 31.3$ & $21.0 \pm 16.1$ & $<0.001^{*}$ \\
\hline $\operatorname{PLT}\left(10^{3} / \mathrm{mm}^{3}\right)$ & $371.0 \pm 135.2$ & $269.5 \pm 77.6$ & $<0.001^{*}$ \\
\hline
\end{tabular}


Clarke et al. (25) found that RDW levels were higher in Crohn's patients compared to UC patients (14.9\% versus $14.3 \%$ ) and they associated this result with malabsorption, which is an additional cause of anemia in Crohn's patients. According to the data of their study, they reported that RDW values may be a marker in the separation of UC and Crohn's (25). Another study determined the RDW cut value at 14.45 with $70 \%$ sensitivity and $56 \%$ specificity in the differentiation of Crohn's disease from UC (7). In our study, there were no significant differences in RDW and other inflammatory parameters between UC and Crohn's patients in the active period.

Among our active IBD patients, RDW, CRP, ESR values and platelet counts were significantly higher in patients with anemia (37.9\%). The result of our data shows that anemia increases in parallel with the severity of the disease. Song et al. (6) showed that RDW correlates with disease activity in anemic and non-anemic IBD patients; They found that RDW was the best independent indicator for predicting disease activity in Crohn's patients without anemia (6). However, in other studies, RDW was an important determinant as an indicator of active UC, while it was stated that CRP was the most sensitive and specific parameter in the evaluation of active disease for Crohn's patients $(5,26)$.

According to our data, ESR, CRP and RDW values were significantly higher during the activity period of UC and Crohn's disease than during the remission period; a strong correlation was found between the severity of disease activity and ESR and CRP in both groups, but no correlation was found between them and RDW values.

\section{CONCLUSION}

We found that RDW values were high during activity periods of IBD patients, and declined to normal values during remission periods. According to our results, RDW as a cheap tool can be a useful marker for activity monitoring, recurrence prediction, and treatment monitoring of IBD patients when evaluated together with other inflammation parameters.

Ethics Committee Approval: The analysis of the data has been approved by the Ethics Committee of Taksim Training and Research Hospital, which confirms that the study complies with the ethical rules of the Declaration of Helsinki (approval number: 36, date: 10.04.2019).

Informed Consent: Retrospective study.

Peer-review: Externally peer-reviewed.

Author Contributions: Design - D.Ö.K., M.K.; Data Collection and/ or Processing - D.Ö.K., M.K.; Analysis and/or Interpretation - D.Ö.K.; Literature Search - D.Ö.K., M.K.; Writing Manuscript - D.Ö.K.

Conflict of Interest: No conflict of interest was declared by the authors.

Financial Disclosure: The authors declared that this study received no financial support.

\section{REFERENCES}

1. Guan Q. A Comprehensive Review and update on the pathogenesis of inflammatory bowel disease. J Immunol Res 2019; 7247238.
2. Kulnigg S, Gasche C. Systematic review: managing anaemia in Crohn's disease. Aliment Pharmacol Ther 2006; 24: 1507-23.

3. Vermeire S, Van Assche G, Rutgeerts P. Laboratory markers in IBD: useful, magic, or unnecessary toys? Gut 2006; 55: 426-31.

4. Cabrera-Abreu J, Davies P, Matek Z, Murphy MS. Performance of blood tests in diagnosis of inflammatory bowel disease in a specialist clinic. Arch Dis Child 2004; 89: 69-71.

5. Cakal B, Akoz AG, Ustundag Y, Yalinkilic M, Ulker A, Ankarali H. Red cell distribution width for assessment of activity of inflammatory bowel disease. Dig Dis Sci 2009; 54: 842-7.

6. Song CS, Park II D, Yoon MY, Seok HS, Park JH, Kim HJ, et al. Association between red cell distribution width and disease activity in patients with inflammatory bowel disease. Digest Dis Sci 2011; 57: 1033-8.

7. Arhan M, Önal KI, Taş A, Kurt M, Kalkan IH, Özin Y, et al. The role of red cell distribution width as a marker in inflammatory bowel disease. Turk J Med Sci 2011; 41: 227-34.

8. Evans TC, Jehle D. The red blood cell distribution width. J Emerg Med. 1991; 9(Suppl 1): 71-4.

9. Sategna GC, Scaglione N, Martini S. Red cell distribution width as a marker of coeliac disease: a prospective study. Eur J Gastroenterol Hepatol 2002; 14: 177-81.

10. Spell DW, Jones DV Jr, Harper WF, Bessman JD. The value of a complete blood count in predicting cancer of the colon. Cancer Detect Prev 2004; 28: $37-42$.

11. Goyal H, Lippi G, Gjymishka A, John B, Chhabra R, May E. Prognostic significance of red blood cell distribution width in gastrointestinal disorders. World J Gastroenterol 2017; 23: 4879-91.

12. Lippi G, Mattiuzzi C, Cervellin G. Learning more and spending less with neglected laboratory parameters: the paradigmatic case of red blood cell distribution width. Acta Biomed 2017; 87: 323-8.

13. Felker GM, Allen LA, Pocock SJ, Shaw LK, McMurray JJV, Pfeffer MA, et al. Red cell distribution width as a novel prognostic marker in heart failure data from the CHARM program and the Duke databank. J Am Coll Cardiol 2007; 50: 41-7.

14. Patel KV, Ferrucci L, Ershler WB, Longo DL, Guralnik JM. Red cell distribution width and the risk of death in middle-aged and older adults. Arch Intern Med 2009; 169: 515-23.

15. Agarwal S. Red cell distribution width, inflammatory markers and cardiorespiratory fitness: Results from the National Health and Nutrition Examination Survey. Indian Heart J 2012; 64: 380-7.

16. Oliveira AM, Cardoso FS, Rodrigues CG, Santos L, Martins A, de Deus JR, et al. Can red cell distribution width be used as a marker of crohn's disease activity? GE Port J Gastroenterol 2016; 23: 6-12.

17. Lippi G, Targher G, Montagnana M, Salvagno GL, Zoppini G, Guidi GS, et al. Relation between red blood cell distribution width and inflammatory biomarkers in a large cohort of unselected outpatients. Arch Pathol Lab Med 2009; 133: 628-32.

18. Ayan NN, Savaş Z, Bireroğlu N, Keleş A, Aksoy N, Serin NÖ. Demir Eksikliği Anemisi Olan Kadınlarda Tedavi Öncesi ve Sonrası Trombosit Değerlerinin Karşılaştırılması. Jarem 2015; 5: 94-6.

19. Mahida YR, Wu K, Jewell DP. Enhanced production of interleukin 1-b by mononuclear cells isolated from mucosa with active ulcerative colitis of Crohn's disease. Gut 1989; 30: 835-8.

20. MacDonald TT, Hutchings $P$, Choy MY, Murch S, Cooke A. Tumour necrosis factor-alpha and interferon-gamma production measured at the single cell level in normal and inflamed human intestine. Clin Exp Immunol 1990; 81: 301-5.

21. Strong SA, Pizarro TT, Klein JS, Cominelli F, Fiocchi C. Proinflammatory cytokines differentially modulate their own expression in human intestinal mucosal mesenchymal cells. Gastroenterology 1998; 114: 1244-56.

22. Schreiber S, Howaldt S, Schnoor M, Nikolaus S, Bauditz J, Gasché C, et al. Recombinant erythropoietin for the treatment of anemia in inflammatory bowel disease. N Engl J Med 1996; 334: 619-24. 
23. Weiss G, Gasche C. Pathogenesis and treatment of anemia in inflammatory bowel disease. Haematologica 2010; 95: 175-8.

24. Antunes $C V$, Hallack Neto $A E$, Nascimento CR, Chebli LA, Moutinho ILD, do Valle Pinheiro B, et al. Anemia in inflammatory bowel disease outpatients: prevalence, risk factors, and etiology. Biomed Res Int 2015; 2015: 728925
25. Clarke K, Sagunarthy R, Kansal S. RDW as an additional marker in inflammatory bowel disease/undifferentiated colitis. Dig Dis Sci 2008; 53 : 2521-3.

26. Ipek S, Cekic C, Alper E, Coban E, Eliacik E, Arabul M, et al. Can red cell distribution width be a marker of disease activity in ulcerative colitis? Int J Clin Exp Med 2015; 8: 13848-53. 